\title{
Aqueous Homo- and Copolymerization of Ethylene by Neutral Nickel(II) Complexes
}

\author{
Florian M. Bauers and Stefan Mecking* \\ Institut für Makromol ekulare Chemie und Freiburger Materialforschungszentrum der \\ Albert-Ludwigs-Universität Freiburg, Stefan-Meier-Str. 31, D-79104 Freiburg, Germany
}

\begin{abstract}
Aqueous coordination polymerization of ethylene by different neutral nickel(II) complexes $[(X \wedge O) N i R(L)](X=P$ : type $\mathbf{1} ; X=N$ : type 2$)$ was investigated. With catalyst precursors of type $\mathbf{1}$, productivities and molecular weights were reduced by comparison to conventional polymerization in organic solvents. This effect results to a large extent from a lowering of the chain growth rate due to a low concentration of ethylene at the catalytically active centers in the aqueous polymerization. The catalysts are stable in water for hours. Stable latices of low-molecular-weight linear polyethylene were obtained with a hydrophilic complex of type 1 in an emulsion-type polymerization ( $\mathrm{M}_{\mathrm{w}} \mathrm{ca} .3 \times 10^{3} \mathrm{~g}$ $\mathrm{mol}^{-1}, \mathrm{M}_{\mathrm{w}} / \mathrm{M}_{\mathrm{n}} 2-3$; solids content of polymer dispersions up to $10 \%$ ). With complexes of type $\mathbf{2}$, productivities in aqueous ethylene polymerization were al so reduced by comparison to polymerization in organic solvents. However, moderately branched semicrystalline polymers of high molecular weight are accessible $\left(\mathrm{M}_{\mathrm{n}}>10^{4} \mathrm{~g} \mathrm{~mol}^{-1}\right)$. E mploying norbornene as a comonomer, high-molecular-weight amorphous copolymers were obtained in water as a reaction medium. Ethylene solubility in water-acetone mixtures was estimated experimentally.
\end{abstract}

\section{Introduction}

Emulsion and suspension polymerization of olefinic monomers are carried out on a vast scale. ${ }^{1}$ The use of water as a dispersing medium offers a unique combination of features, such as effective transfer of the heat of reaction, high polarity and immiscibility with many monomers and polymers, and formation of micelles as well as effective stabilization of hydrophobic polymer particles by surfactants. The environmental friendliness and nonflammability of water are advantageous, also with regard to the numerous applications of latices involving film formation upon evaporation of the dispersing medium. To date, aqueous polymerization reactions are carried out by free radical processes exclusively. Transitionmetal catalyzed coordination polymerization reactions in water ${ }^{2}$ have received less attention, as the early transition metal catalysts ${ }^{3}$ used commercially for polyolefin production are extremely sensitive to moisture. Carrying out such reactions in aqueous emulsion or suspension is a highly attractive goal, however, as many polymer microstructures are not available by other means than coordination polymerization.

Late transition metal complexes are generally more tolerant toward polar media due to their less oxophilic nature. Concerning late transition metal catalyzed C-C linkage of ethylene in general (i.e., in nonaqueous organic reaction media), dimers or oligomers are obtained usually due to the propensity of late transition metal alkyl complexes for $\beta$-hydride elimination. ${ }^{4}$ Only a limited number of catalysts for the polymerization to high molecular weight products are known. ${ }^{5}$ Most of them are based either on neutral nickel(II) complexes (exemplified by structures $\mathbf{1}$ and 2 ; see Chart 1) ${ }^{6,7}$ of formally monoanionic bidentate ligands or on cationic nickel, palladium, iron, or cobalt complexes $(\mathbf{3}, \mathbf{4})^{8}$ of neutral multidentate ligands with bulky substituted

\footnotetext{
* To whom correspondence should be addressed. E-mail: mecking@uni-freiburg.de.
}

nitrogen donor atoms. ${ }^{9}$ The recent discovery of late transition metal catalysts based on structures $\mathbf{2}, \mathbf{3}$, and 4 has spurred an intense search for late transition metal olefin polymerization catalysts based on other ligand structures, also employing high-throughput screening techniques. ${ }^{10} \mathrm{~F}$ or our investigation of ethylene polymerization in water we have utilized complexes derived from the aforementioned known structures 1-3, varying the ligands to adjust their water solubility. ${ }^{15}$

Regarding the stability of neutral nickel(II) complexes toward polar media in general, catalysts for ethylene oligomerization (basis to structural type $\mathbf{1}$ ) are highly stable in alcohol solvents, as illustrated by their large scale application using 1,4-butandiole as a polar catalyst phase to enable simple separation from the olefin products. ${ }^{11}$ Catalyst separation has been sought to be improved by using methanol or water-containing methanol $(20: 80 \mathrm{v} / \mathrm{v})$ as a catalyst phase, in which the catalysts are also stable. ${ }^{11 b, 12}$ (On the other hand, the catalyst $\left[\left\{\kappa^{2} \mathrm{P}, \mathrm{O}-\mathrm{Ph}_{2} \mathrm{P}-\mathrm{C}(\mathrm{H})=\mathrm{C}(\mathrm{Ph})-\mathrm{O}\right\} \mathrm{NiPh}\left(\mathrm{PPh}_{3}\right)\right]$, removal of $\mathrm{PPh}_{3}$ by phosphine scavengers for ethylene polymerization, was reported to be completely inactive in the presence of water. ${ }^{6 g}$ ) Polymerization catalysts of type $\mathbf{2}$ were reported independently by Grubbs et al. and J ohnson et al. ${ }^{7}$ Such catalysts have been noted to display a certain stability toward small amounts of added water. ${ }^{7 c}$ Utilization of the aforementioned unique benefits of water as a medium for polymerization reactions usually requires a largely aqueous medium, i.e., the presence of only relatively small amounts of organic solvents or their complete absence. Regarding ethylene polymerization in aqueous media literature data were less encouraging. A very slow (ca. 1 turnover/ day) coordination polymerization of ethylene in water catalyzed by a rhodium complex has previously been investigated. 13,14 Only recently, successful homopolymerization of ethylene by neutral nickel(II) or by cati onic palladium(II) complexes in water as a reaction medium has been reported. ${ }^{15,16}$ With the $\mathrm{Ni}$ (II) catalysts, 
<smiles>[Y]C1=C([X])P(I)(c2ccccc2)(c2ccccc2)OC1I</smiles>

e.g.

$\mathrm{X}=\mathrm{H}, \mathrm{SO}_{3} \mathrm{Na}$

$\mathrm{Y}=$ aryl, $\mathrm{OR} "$

$\mathrm{L}=\mathrm{PR}_{3}$, subst. pyridine, $\mathrm{CR}_{2} \mathrm{PR}_{3}$

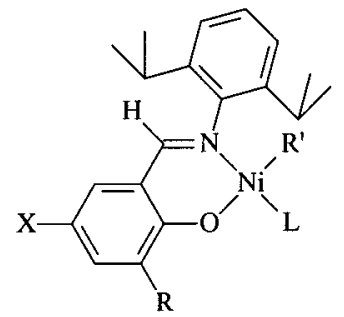

2

e.g.

$\mathrm{X}=\mathrm{H}, \mathrm{NO}_{2}$

$\mathrm{R}=\mathrm{H}$, aryl

$\mathrm{R}^{\prime}=\mathrm{Me} ; \mathrm{L}=\mathrm{CH}_{3} \mathrm{CN}$

$\mathrm{R}^{\prime}=\mathrm{Ph} ; \mathrm{L}=\mathrm{PPh} 3$

activation of $\mathrm{PR}_{3}$-complexes for polymerization

by phosphine scavengers
Chart 1 (n)

3

$\mathrm{M}=\mathrm{Ni}, \mathrm{Pd}$

$\mathrm{R}^{\prime}=\mathrm{Me}, \mathrm{H}, 0.5$ napht-1,8-diyl

$\mathrm{R}={ }^{\mathrm{i}} \mathrm{Pr}, \mathrm{Me}$

$\mathrm{Y}^{-}=\mathrm{BAr}_{4}^{\mathrm{F}}, \mathrm{SbF}_{6}{ }^{-}$
$\mathrm{L}=\mathrm{OEt}_{2}, \mathrm{R}^{\prime \prime} \mathrm{CN}$

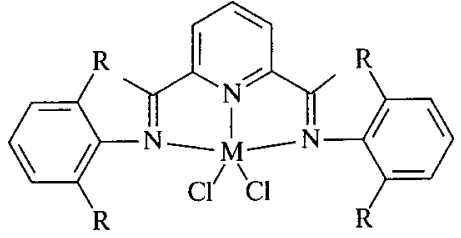

4

$\mathrm{M}=\mathrm{Fe}, \mathrm{Co}$

$\mathrm{R}={ }^{\mathrm{i}} \mathrm{Pr}, \mathrm{Me}$

activation e.g. by methylalumoxane

\section{Chart 2}<smiles>Cc1ccc(C2=C([O-])P(c3ccccc3)(c3ccccc3)(c3ccccc3)[N+]2([O+])c2ccccc2)cc1</smiles>

la: $\mathrm{M}^{+}=\mathrm{Na}^{+}$(hydrophilic)

1b: $\mathrm{M}^{+}=\mathrm{H}_{33} \mathrm{C}_{16} \mathrm{NMe}_{3}^{+}$(lipophilic)

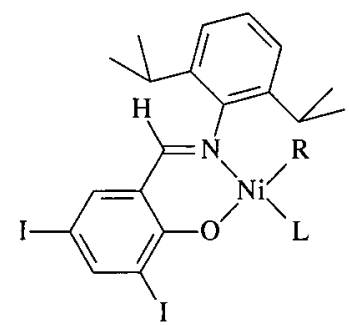

2a: $\mathrm{R}=\mathrm{Ph} ; \mathrm{L}=\mathrm{PPh}_{3}$

2b: $\mathrm{R}=\mathrm{Me} ; \mathrm{L}=$ pyridine phosphine scavenger for polymerization with $1 \mathbf{a}, \mathbf{1 b}$ and $\mathbf{2 a}$ : $\left[\mathrm{Rh}\left(\mathrm{CH}_{2}=\mathrm{CH}_{2}\right)_{2}\right.$ (acac)]

experiments were also carried out in 50:50 water/ acetone mixtures and in neat organic solvents.

Polymerization by Complexes $\mathbf{1}$. Polymerization results with complexes $\mathbf{1}$ are given in Table 1 . By comparison to traditional polymerization in organic solvents (entries 10-12), in water as a reaction medium under otherwise identical reaction conditions (ethylene pressure, temperature) polymer yields and molecular weights are significantly lower. In the aqueous polymerization, the catalysts are still active after several hours of polymerization in water (entries 1 vs 2 and 6 vs 7). Thus, the lower productivities in water by comparison to polymerization in toluene or acetone are not due to a conceivable rapid irreversible deactivation of the catalyst in the initial stages of the polymerization. It seemed straightforward to ascribe the observed effect to a (reversible) blocking of coordination sites by binding of water as a ligand. However, it must also be considered that the catalysts employed are generally very sensitive toward ethylene concentration: for ethylene polymerization by neutral nickel(II) P,O chelate complexes in toluene, a strong positive dependence of chain growth rate on ethylene concentration has been observed at moderate pressures.69 For the particular catalyst precursors employed in this study, this behavior is illustrated by entries 8-10 in neat acetone as a solvent. In terms of Scheme 1, this kinetic behavior translates to an effective dependence of monomer binding on ethylene concentration at the metal site (i.e., regarding monomer binding as an equilibrium (b), $\mathrm{K}_{1} \mathrm{c}$ (ethylene) $<1)$. Regarding polymer molecular weights, analysis of 
Table 1. Polymerization Results with Catalysts $\mathbf{1}^{\mathrm{a}}$

\begin{tabular}{|c|c|c|c|c|c|c|c|c|c|c|c|}
\hline \multirow[b]{2}{*}{$\begin{array}{c}\text { entry } \\
\text { no. }\end{array}$} & \multicolumn{5}{|c|}{ reaction conditions } & \multicolumn{6}{|c|}{ results } \\
\hline & cat. & $\begin{array}{c}\mathrm{n} \text { (cat.)/ } \\
\mu \mathrm{mol}\end{array}$ & $\begin{array}{l}\text { ethylene } \\
\text { press./bar }\end{array}$ & $\begin{array}{l}\text { reaction } \\
\text { medium }\end{array}$ & $\begin{array}{c}\text { solvent used } \\
\text { for addition of } \\
\text { catalyst }^{d}\end{array}$ & $\begin{array}{c}\text { reaction } \\
\text { time/h }\end{array}$ & $\begin{array}{l}\text { polymer } \\
\text { yield/g }\end{array}$ & $\begin{array}{c}\text { productivity/ } \\
\text { (mol (ethylene) } \\
\text { mol (cat.) }{ }^{-1} \text { ) }\end{array}$ & $\begin{array}{c}\text { av activity/ } \\
\text { (mol (ethylene) } \\
\text { mol (cat.) }{ }^{-1} \mathrm{~h}^{-1} \text { ) }\end{array}$ & $\begin{array}{c}\mathrm{M}_{\mathrm{n}} /\left(\mathrm{g} \mathrm{mol}^{-1}\right) \\
\left(\mathrm{M}_{\mathrm{w}} / \mathrm{M}_{\mathrm{n}}\right)\end{array}$ & $\begin{array}{c}\mathrm{M}_{\mathrm{w}} / \\
\left(\mathrm{g} \mathrm{mol}^{-1}\right)\end{array}$ \\
\hline 1 & 1a & 130 & 50 & $\mathrm{H}_{2} \mathrm{O}$ /acetone 50:50 & & 1.5 & 2.5 & 680 & 450 & $1.1 \times 10^{3}(2.3)$ & $2.5 \times 10^{3}$ \\
\hline 2 & 1a & 121 & 50 & $\mathrm{H}_{2} \mathrm{O} /$ acetone 50:50 & & 3 & 3.2 & 940 & 310 & $1.2 \times 10^{3}(3.9)$ & $4.6 \times 10^{3}$ \\
\hline 3 & 1b & 73 & 50 & $\mathrm{H}_{2} \mathrm{O}$ /acetone $50: 50$ & & 2 & 2.0 & 980 & 490 & $\mathrm{~b}$ & b \\
\hline 4 & $1 a$ & 108 & 50 & water & acetone (5\%) & 2 & 2.2 & 710 & 360 & $1.0 \times 10^{3}(2.3)$ & $2.2 \times 10^{3}$ \\
\hline 5 & la & 89 & 50 & water & toluene (5\%) & 2 & 5.9 & 2360 & 1180 & $1.0 \times 10^{3}(3.1)$ & $3.0 \times 10^{3}$ \\
\hline 6 & 1b & 116 & 50 & water & toluene (5\%) & 1.5 & 1.0 & 310 & 210 & b & b \\
\hline 7 & $\mathbf{1 b}$ & 104 & 50 & water & toluene (5\%) & 3 & 1.6 & 550 & 180 & $1.0 \times 10^{3}(3.3)$ & $3.2 \times 10^{3}$ \\
\hline 8 & $1 \mathbf{a}$ & 45 & 2 & acetone & & 2 & 0.7 & 550 & 275 & $\mathrm{~b}$ & $\mathrm{~b}$ \\
\hline 9 & $1 a$ & 38 & 6 & acetone & & 2 & 1.3 & 1230 & 615 & $1.9 \times 10^{3}(2.4)$ & $4.5 \times 10^{3}$ \\
\hline 10 & la & 26 & 50 & acetone & & 2 & 22.2 & $30440^{c}$ & $15220^{c}$ & $3.8 \times 10^{3}(25)$ & $9.4 \times 10^{4}$ \\
\hline 11 & $1 a$ & 12 & 50 & toluene & & 2 & 9.0 & 26680 & 13340 & $1.4 \times 10^{4}(42)$ & $5.8 \times 10^{5}$ \\
\hline 12 & $\mathbf{1 b}$ & 9 & 50 & toluene & & 1.75 & 5.2 & 20600 & 11780 & $5.4 \times 10^{3}(5.3)$ & $2.9 \times 10^{4}$ \\
\hline
\end{tabular}

a Reaction conditions: $70^{\circ} \mathrm{C}$; total volume of water and/or organic solvent: $100 \mathrm{~mL}$; phosphine scavenger $\left[\mathrm{Rh}\left(\mathrm{CH}_{2}=\mathrm{CH}\right)_{2}(\mathrm{acac})\right](\mathrm{Ni} /$ Rh 2:1). ${ }^{b}$ Not determined. ${ }^{c}$ Possibly mass transfer limited. ${ }^{d}$ Solvent used for addition of the $\mathrm{Ni}(\mathrm{II})$ catalyst precursor and the phosphine scavenger (vol \%).

Scheme 1. Chain Growth in Ethylene Polymerization $\left(\mathbf{R}, \mathbf{R}^{\prime}=\right.$ Growing Polymer Chain)

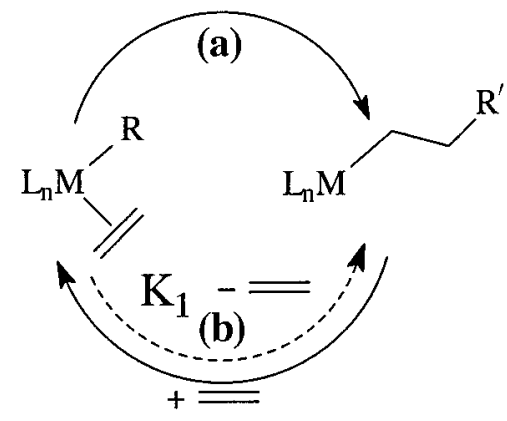

the experimental data is complicated by the broad molecular weight distributions obtained in comparative experiments in neat organic solvents. Nonetheless, it can be noted that a comparison of the productivities and observed molecular weights in organic solvents and water, respectively, gives no indication of strongly increased rates of chain transfer; rather, the lowering of molecular weights in the aqueous polymerization can be ascribed to the reduced rate of chain growth. ${ }^{19}$ In the multiphase mixture represented by such polymerization reactions (liquid phase containing dissolved ethylene; water-immiscible semicrystalline polymer swollen with monomer and optionally organic solvent; catalyst initially dissolved or suspended in the aqueous phase or in toluene droplets and confined in the polymer to a variable extent during the polymerization reaction), concentration of the monomer in the liquid phase is obviously not necessarily identical with concentration at the catalytically active center. For active sites exposed to the liquid phase, ethylene concentration in the latter will be relevant. For active sites confined in the polymer phase, ideal thermodynamic equilibrium concentration of the monomer in the polymer for a given set of reaction conditions (ethylene pressure, temperature) but also mass transfer of ethylene across the liquid-polymer interphase and within the polymer can be significant. The significance of mass transfer limitations can generally be expected to increase with increasing polymer crystallinity and decreasing concentration of monomer in the liquid phase. ${ }^{20}$ In view of the high polymer crystallinity and the high sensitivity of the neutral $\mathrm{Ni}(\mathrm{II})$ catalyst toward ethylene concentration, in the real-life system investigated the strong lowering of ethylene concentration in the aqueous phase by comparison to traditional polymerization in organic solvents must be expected to affect monomer concentration also at metal centers confined in the polymer phase to a significant extent. In agreement herewith, no dramatic effect of the variation of the hydrophilicity of the catalyst on the outcome of polymerization was observed (vide infra). Because of the markedly different exposure of the different catalyst precursors to the aqueous phase in these experiments, a strongly varying sensitivity toward blocking of coordination sites by water should be observed if this were the prime reason for the observed lowering of propagation rate in aqueous polymerizations. Estimation of ethylene solubility (vide supra) showed that ethylene concentration in neat acetone at 6 bar is similar to concentration in a 50:50 (v/v) water/acetone mixture at 50 bar. Similar productivities and molecular weights were observed in these aqueous and nonaqueous polymerizations (runs 1 and 2 vs 9). From the data obtained we conclude that the observed lowering of productivity and also polymer molecular weight in aqueous polymerization is due to a large extent to a low concentration of ethylene at the catalytically active metal centers. Thus, in general for polymerization in water a high catalytic activity at low ethylene concentrations is desirable; i.e., in addition to a high rate of insertion in the alkyl-olefin complex (Scheme 1, (a)), a high propensity for binding of ethylene (b) is also particularly advantageous.

Complex $\mathbf{1 b}$ with a large tetraalkylammonium counterion represents a lipophilic analogue of 1a: whereas $\mathbf{l a}$ is extracted to the aqueous phase upon adding water to a toluene solution of the complex $\mathbf{1 b}$ remains in the organic phase. Overall, no dramatic differences in polymer molecular weight and productivity are observed with $\mathbf{1 b}$ vs $\mathbf{l a}$ in the water/acetone and also in the water/toluene systems. (In the latter, employing a lipophilic complex may result in an "encapsulation" in the small amount of water-immiscible organic phase to a certain extent.) These results show that the increased exposure of $\mathbf{l a}$ to the aqueous phase is not disadvantageous, confirming the aforementioned observations on catalyst stability.

It should be noted that the broad molecular weight distributions obtained with catalyst precursors of type $\mathbf{1}$ in comparative experiments in toluene are in accord with literature reports; the origin of this effect has not been identified clearly. ${ }^{6 g, h}$ By contrast, the lower molecular weight materials obtained with $\mathbf{1}$ in water display relatively narrow molecular weights distributions, typical of single site catalysts. The linear poly- 
Table 2. Polymerization Results with Catalysts $\mathbf{2}^{\mathrm{a}}$

\begin{tabular}{|c|c|c|c|c|c|c|c|c|c|c|c|c|}
\hline \multirow[b]{2}{*}{$\begin{array}{l}\text { entry } \\
\text { no. }\end{array}$} & \multicolumn{7}{|c|}{ reaction conditions } & \multicolumn{5}{|c|}{ results } \\
\hline & cat. & $\begin{array}{c}\mathrm{n} \text { (cat.)/ } \\
\mu \mathrm{mol}\end{array}$ & $\begin{array}{c}\text { ethylene } \\
\text { press./bar }\end{array}$ & $\begin{array}{l}\text { reaction } \\
\text { medium }\end{array}$ & $\begin{array}{l}\text { solvent used } \\
\text { for addition } \\
\text { of cat. }{ }^{d}\end{array}$ & $\begin{array}{l}\text { react. } \\
\text { time/h }\end{array}$ & $\begin{array}{l}\text { react. } \\
\text { temp/ } /{ }^{\circ} \mathrm{C}\end{array}$ & $\begin{array}{l}\text { polymer } \\
\text { yield/g }\end{array}$ & $\begin{array}{c}\text { productivity/ } \\
\text { (mol (ethylene) } \\
\text { mol (cat.) }{ }^{-1} \text { ) }\end{array}$ & $\begin{array}{c}\text { av activity/ } \\
\text { (mol (ethylene) } \\
\text { mol (cat.) })^{-1} \mathrm{~h}^{-1} \text { ) }\end{array}$ & $\begin{array}{c}\mathrm{M}_{\mathrm{n}} /\left(\mathrm{g} \mathrm{mol}^{-1}\right) \\
\left(\mathrm{M}_{\mathrm{w}} / \mathrm{M}_{\mathrm{n}}\right)\end{array}$ & $\begin{array}{l}M_{w} /(g \\
\left.m^{-1}\right)\end{array}$ \\
\hline 1 & $2 a$ & 19 & 50 & water & pentane (10\%) & 2 & 70 & 1.9 & 3490 & 1745 & $1.0 \times 10^{5}(4.1)$ & $4.1 \times 10^{5}$ \\
\hline $2^{c}$ & $2 a$ & 41 & 50 & water & toluene ( $5 \%)$ & 3 & 25 & 10.6 & 9220 & 3070 & $\mathrm{~b}$ & $\mathrm{~b}$ \\
\hline 3 & $2 a$ & 36 & 50 & water & acetone (10\%) & 2 & 70 & 0.7 & 710 & 355 & $5.7 \times 10^{4}(6.1)$ & $3.5 \times 10^{5}$ \\
\hline 4 & $2 a$ & 56 & 50 & $\mathrm{H}_{2} \mathrm{O} /$ acetone $50: 50$ & & 1 & 50 & 2.2 & 1420 & 1420 & $1.2 \times 10^{4}(1.5)$ & $1.8 \times 10^{4}$ \\
\hline 5 & $2 a$ & 71 & 50 & $\mathrm{H}_{2} \mathrm{O} /$ acetone $50: 50$ & & 2 & 50 & 3.0 & 1500 & 750 & $1.4 \times 10^{4}(1.6)$ & $2.3 \times 10^{4}$ \\
\hline 6 & $2 a$ & 37 & 50 & pentane & & 2 & 70 & 10.7 & 10310 & 5155 & $1.1 \times 10^{5}(3.7)$ & $4.1 \times 10^{5}$ \\
\hline 7 & $2 a$ & 21 & 50 & acetone & & 1 & 50 & 3.0 & 5110 & 5110 & $b$ & $\mathrm{~b}$ \\
\hline 8 & $2 a$ & 21 & 50 & acetone & & 2 & 50 & 5.2 & 8880 & 4440 & $\mathrm{~b}$ & $\mathrm{~b}$ \\
\hline 9 & $2 a$ & 35 & 8 & toluene & & 2 & 50 & 0.7 & 750 & 375 & $1.9 \times 10^{4}(2.3)$ & $4.3 \times 10^{4}$ \\
\hline 10 & $2 a$ & 35 & 15 & toluene & & 2 & 50 & 1.3 & 1280 & 640 & b & b \\
\hline 11 & $2 a$ & 37 & 50 & toluene & & 2 & 50 & 16.9 & 16280 & 8140 & $\mathrm{~b}$ & $\mathrm{~b}$ \\
\hline 12 & $\mathbf{2 b}$ & 80 & 50 & water & acetone (5\%) & 1 & 50 & 2.9 & 1280 & 1280 & $1.2 \times 10^{5}(2.6)$ & $3.1 \times 10^{5}$ \\
\hline
\end{tabular}

a Total volume of water and/or organic solvent: $100 \mathrm{~mL}$; phosphine scavenger $\left[\mathrm{Rh}\left(\mathrm{CH}_{2}=\mathrm{CH}_{2}\right)_{2}(\mathrm{acac})\right](\mathrm{Ni} / \mathrm{Rh} 2: 1)$ (entries 1-11). ${ }^{\mathrm{b}} \mathrm{Not}$ determined. ${ }^{\mathrm{C}} 2 \mathrm{~g}$ of poly(vinyl alcohol) added (Fluka, $10^{5} \mathrm{~g} \mathrm{~mol}^{-1}, 86-89 \mathrm{~mol} \%$ hydrolyzed). ${ }^{\mathrm{d}}$ Solvent used for addition of the $\mathrm{Ni}(\mathrm{II})$ catalyst precursor and the phosphine scavenger (vol \%)

ethylenes obtained in water and in comparative experiments in organic solvents were investigated by hightemperature ${ }^{1} \mathrm{H}$ and ${ }^{13} \mathrm{C}$ NMR analysis. For some low molecular weight samples, terminal vinyl end groups and also internal olefinic moieties could be observed. Overall, the polymer microstructure does not indicate any unexpected effect of water on the modes of chain growth or chain transfer. The relatively low molecular weight of the materials obtained with complexes $\mathbf{1}$ in water results in an observable lowering of the melting point, determined by DSC. Typically, a broad melt transition with a peak $\mathrm{T}_{\mathrm{m}}$ in the range of $121-127^{\circ} \mathrm{C}$ is observed, by comparison to $\mathrm{T}_{\mathrm{m}} 133^{\circ} \mathrm{C}$ for higher molecular weight material obtained in toluene. However, the onset of these thermal transitions was found to occur clearly above the polymerization temperature of $70{ }^{\circ} \mathrm{C}$. It can be concluded that polyethylene dispersions (vide infra) are formed directly during the polymerization reaction (as opposed to a conceivable partial solidification during cooling after the reaction).

Polymerization by Complexes $\mathbf{2}$. Polymerization results obtained with the N,O chelate complexes $\mathbf{2}$ are given in Table 2 (it should be noted that the iodo substituents of the chelating ligand render $\mathbf{2}$ soluble in pentane). Again, in experiments carried out under otherwise identical conditions (50 bar ethylene), polymer yields are lowered in water by comparison to conventional polymerization in organic solvents. However, polymer molecular weights are markedly higher by comparison with the aqueous polymerization reactions with catalysts $\mathbf{1}$ investigated. For the first time, high molecular weight semicrystalline polyethylene is accessible in an aqueous coordination polymerization. Similar to complexes of type $\mathbf{1}$, polymerization activity of $\mathrm{N}, \mathrm{O}$ chelate complexes in organic solvents has been noted to be strongly dependent upon ethylene concentration, ${ }^{7 d}$ and for the particular catalyst precursor $\mathbf{2 a}$ employed this behavior is illustrated in detail by entries 9-11. Thus, lower activity in water by comparison to polymerization in toluene or acetone can again be related to a lower concentration of ethylene at the active site. However, irreversible catalyst deactivation in water as a reaction medium al so appears to be significant for the salicylal dimine-substituted catalysts: runs with different reaction times (entries 4 and 5) indicate that within $1 \mathrm{~h}$ or less the catalyst is largely deactivated. By comparison, in neat acetone the catalyst was still active after $2 \mathrm{~h}$ (entries 7 and 8). Employing methyl complex $\mathbf{2 b}$ as a single-component catalyst precursor for aqueous polymerization (entry 12 ), similar results as with $\mathbf{2} \mathbf{a}$ are obtained.

High-temperature ${ }^{1} \mathrm{H}$ and ${ }^{13} \mathrm{C}$ NMR analysis of the polymers obtained in aqueous polymerizations reveals a branched structure consisting mainly of methyl branches (5-20 branches/1000 carbon atoms). Basically the same structure is al so found for materials obtained in comparative experiments in organic solvents, in accordance with previous reports by J ohnson et al. and Grubbs et al. ${ }^{7}$ These results again indicate no dramatic effect of water on the basic modes of chain growth and branching. Crystallinity of a typical moderately branched material (10 branches/1000 carbon atoms) obtained in water amounts to ca. $50 \%$ (determined by DSC; $\mathrm{T}_{\mathrm{m}}=$ $\left.127^{\circ} \mathrm{C}\right)$.

Emulsion Polymerization. A particularly intruiging aspect of aqueous polymerization is the possibility to prepare polymer latices. Addition of anionic (SDS; Bayer K 30, i.e., sodium alkylsulfonates) or neutral surfactants (e.g., Triton X-100) to polymerizations employing complexes $\mathbf{1}$ or $\mathbf{2}$ generally did not result in a disadvantageous effect on polymer yields. With $\mathbf{1 a}$, stable latices of the low-molecular-weight linear polyethylenes formed are obtained. Productivities and polymer molecular weights resemble those of the suspension-type polymerizations given in Table 1. During polymerization, no significant amount of coagulate was formed, and the resulting latices are stable for a month or longer. Solids contents of $10 \%$ were observed without optimization. From the extensive literature on free radical emulsion polymerization, ${ }^{1}$ it is evident that the particle formation process (nucleation, stabilization, coagulation) is critical to the preparation of stable polymer dispersions. As previously noted, 1a is hydrophilic and water-soluble. It can be reasoned that the resulting very effective distribution (by comparison to solid particles of a hydrophobic catalyst precursor or solutions of the same in larger non-water-miscible solvent droplets) is advantageous for primary particle formation, leading to stable latices. Particle sizes of these latices are found to be in the range of 80 to several hundred nanometers typically, as observed by dynamic light scattering. This finding is in accordance with results of TEM investigations. As al ready alluded to, the thermal behavior of the polymers demonstrates that polymer latices are formed directly during the polymerization reaction. The preparation of high-molecular-weight lattices will be reported separately. 
Table 3. Ethylene-Norbornene Copolymerizations ${ }^{a}$

\begin{tabular}{|c|c|c|c|c|c|c|c|c|c|c|c|c|c|}
\hline \multirow{4}{*}{$\begin{array}{l}\text { entry } \\
\text { no. }\end{array}$} & \multirow{2}{*}{\multicolumn{6}{|c|}{ reaction conditions }} & \multicolumn{7}{|c|}{ results } \\
\hline & & & & & & & \multirow{3}{*}{$\begin{array}{l}\text { polym } \\
\text { yield/g }\end{array}$} & \multirow{3}{*}{$\begin{array}{l}\text { norbornene } \\
\text { content/mol \% }\end{array}$} & \multirow{2}{*}{\multicolumn{2}{|c|}{ 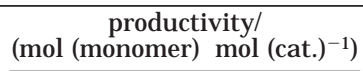 }} & \multirow{3}{*}{$\begin{array}{c}\mathrm{M}_{\mathrm{n}}^{\mathrm{c}} /\left(\mathrm{g} \mathrm{mol}^{-1}\right) \\
\left(\mathrm{M}_{\mathrm{w}} / \mathrm{M}_{\mathrm{n}}\right)\end{array}$} & \multirow{3}{*}{$\begin{array}{c}\mathrm{M}_{\mathrm{w}} \mathrm{c} / \\
\left(\mathrm{g} \mathrm{mol}^{-1}\right)\end{array}$} & \multirow{3}{*}{$\mathrm{T}^{\circ} \mathrm{C}$} \\
\hline & \multirow[b]{2}{*}{ cat. } & \multirow{2}{*}{$\begin{array}{l}\mathrm{n} \text { (cat.)/ } \\
\mu \mathrm{mol}\end{array}$} & \multirow{2}{*}{$\begin{array}{l}\text { ethylene } \\
\text { press./bar }\end{array}$} & \multirow{2}{*}{$\begin{array}{c}\mathrm{n} \text { (norbornene)/ } \\
\text { mmol }\end{array}$} & \multirow{2}{*}{$\begin{array}{l}\text { reaction } \\
\text { medium }\end{array}$} & \multirow{2}{*}{$\begin{array}{l}\text { react. } \\
\text { time/h }\end{array}$} & & & & & & & \\
\hline & & & & & & & & & ethylene & norbornene & & & \\
\hline $1^{d}$ & $2 a$ & 45 & 50 & 53 & watere & 3 & 2.2 & 14 & 1140 & 180 & $8.8 \times 10^{4}(2.2)$ & $1.9 \times 10^{5}$ & -4 \\
\hline $2^{d}$ & $2 a$ & 68 & 50 & 7 & watere & 2 & 1.3 & 6 & 560 & 40 & $3.2 \times 10^{4}(3.0)$ & $9.6 \times 10^{4}$ & \\
\hline 3 & 1b & 84 & 50 & 42 & watere & 3 & 1.0 & 15 & 270 & 50 & $1.8 \times 10^{3}(6.1)$ & $1.1 \times 10^{4}$ & 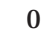 \\
\hline 4 & $2 a$ & 87 & 10 & 106 & toluene & 3 & 6.0 & 19 & 1380 & 330 & $7.7 \times 10^{4}(1.8)$ & $1.4 \times 10^{5}$ & 6 \\
\hline 5 & $\mathbf{1 b}$ & 56 & 10 & 82 & toluene & 3 & 1.5 & 25 & 450 & 150 & $2.0 \times 10^{3}(8.0)$ & $1.6 \times 10^{4}$ & 25 \\
\hline
\end{tabular}

a Reaction conditions: room temperature; total volume of water and/or organic solvent: $100 \mathrm{~mL}$; phosphine scavenger $\left[\mathrm{Rh}\left(\mathrm{CH}_{2}=\mathrm{CH}\right)_{2}(\mathrm{acac})\right]$ (Ni/Rh 2:1). ${ }^{b}$ Not determined. c Referenced to polyethylene standards (universal calibration). ${ }^{d} 1 \mathrm{~g}$ of Triton X-100 added. e Norbornene monomer and catalyst added as mixtures with toluene (run 1: $10 \mathrm{~mL}$; run 2: $5 \mathrm{~mL}$; run 3: $15 \mathrm{~mL}$ ).

Ethylene-Norbornene Copolymerization. Copolymerization of ethylene with other ol efinic comonomers is applied widely to tailor polymer properties, such as the crystallinity. In commercial polyethylenes produced with Ziegler catalysts most often $\alpha$-olefin comonomers are employed. Regarding the neutral nickel(II)-based polymerization catalysts, however, the high chemoselectivity for ethylene often results in a relatively low incorporation of $\alpha$-olefins. Norbornene as a strained cyclool efin can be suited as a comonomer. ${ }^{22,23}$

Results of aqueous copolymerizations are given in Table 3. As norbornene is solid at room temperature, the comonomer was added as a liquid mixture with small amounts of toluene. Ethylene/norbornene copolymerization can be carried out effectively in water as a reaction medium, yielding copolymers with high molar norbornene incorporation (up to $25 \mathrm{~mol} \%$ in the examples shown). The copolymerization of ethylene and norbornene can be carried out with complexes $\mathbf{1}$ or $\mathbf{2}$ as catalyst precursors; however, direct comparison reveals significantly higher activities and polymer molecular weights with the latter complex type. The copolymers given in Table 3 were analyzed by high-temperature ${ }^{13} \mathrm{C}$ NMR. Norbornene units are incorporated largely as isolated units EENEE. For the samples with higher norbornene content al ternating sequences ENENE are also observed. By contrast to the semicrystalline ethylene homopolymers, materials with a sufficient comonomer content are amorphous, as confirmed by wide-angle X-ray scattering (WAXS) of the polymers from runs 1 , 4 , and 5. Glass transition temperatures of the polymers prepared are between -4 and $25^{\circ} \mathrm{C}$ dependent on the content of norbornene. The copolymers form transparent films.

\section{Summary and Conclusions}

In the aqueous coordination polymerization of ethylene by neutral nickel(II) complexes of type $\mathbf{1}$, polymer molecular weight and catalyst productivity are reduced by comparison to polymerization in organic solvents. However, polymerization occurs at reasonably high rates, and in the present study we have not focused on optimization of catalyst performance for aqueous polymerization. Polymerization data imply that the aforementioned effects on activity and polymer molecular weight are due to a large extent to a lowering of the rate of chain growth by a low concentration of ethylene at the catalytically active metal centers in the aqueous polymerization. The catalysts are still active after several hours of polymerization in water. With salicylaldimine-based catalysts of type $\mathbf{2}$, a similar effect on productivity is observed; however, catal yst deactivation in the aqueous polymerization is also apparent in this case. With 2, high molecular weight semicrystalline polyethylene is accessible in aqueous polymerizations. Analyses of the microstructures of the polymers obtained with $\mathbf{1}$ and $\mathbf{2}$ do not reveal an effect of water on the basic modes of chain growth and chain transfer (and for $\mathbf{2}$ also chain branching). Stable latices of low molecular weight linear polyethylene can be formed directly in the polymerization reaction with $\mathbf{1 a}$. Copolymerization with norbornene as a suited comonomer allows for control of polymer crystallinity in aqueous ethylene polymerization. Amorphous high molecular weight ethylene/norbornene copolymers can be obtained in water as a reaction medium.

\section{Experimental Section}

Materials and General Considerations. Nickel(II) complexes were manipulated by standard Schlenk techniques under argon. Ethylene (99.8\%) supplied by Gerling and Holz was used without further purification. Organic solvents were distilled from drying agents (acetone: $\mathrm{P}_{2} \mathrm{O}_{5}$; dichloromethane: $\mathrm{CaH}_{2}$; pentane: $\mathrm{KOH}$; toluene and THF: $\mathrm{Na}$ ) under argon. Deionized water was degassed prior to use.

${ }^{1} \mathrm{H}$ and ${ }^{13} \mathrm{C}$ NMR spectra were recorded on a Bruker $\mathrm{ARX}$ 300 instrument at 300 and $75 \mathrm{MHz}$, respectively. ${ }^{31} \mathrm{P}$ NMR spectra were obtained on a Bruker DRX 500 at $202 \mathrm{M} \mathrm{Hz} .{ }^{1} \mathrm{H}$ and ${ }^{13} \mathrm{C}$ NMR spectra of ethylene homo- and copolymers were obtained in 1,1,2,2-tetrachloroethane- $\mathrm{d}_{2}$ at $122^{\circ} \mathrm{C}$. Resonances were assigned according to refs 24 and 25. Differential scanning calorimetry (DSC) was performed on a Perkin-EImer DSC 7 or on a Pyris 1 DSC at a heating rate of $10 \mathrm{~K} / \mathrm{min}$. DSC data reported are second heats. High-temperature gel permeation chromatography was performed in 1,2,4-trichlorobenzene at $140{ }^{\circ} \mathrm{C}$ using a PL-220 instrument equipped with Mixed Bed PL-columns. Data reported were referenced to polyethylene standards (universal calibration). Dynamic light scattering on dispersions was performed on a Malvern particle sizer. WAXS was performed on a Siemens D 500 apparatus with a $2 \Theta$ distance of 0.1 and a measurement time of $6 \mathrm{~s}$ per point. Ethylene solubilities were estimated using the method described in ref 8d, employing a $100 \mathrm{~mL}$ steel reactor. Essentially, ethylene uptake at 0-40 bar and room temperature into a given amount of solvent was determined by weighing the reactor. The amount of ethylene in the gas phase was corrected for by repeating the experiment, replacing the solvent by the same volume of glass beads.

Catalyst Precursor Synthesis. The phosphorus ylide $\mathrm{Ph}_{3} \mathrm{P}=\mathrm{CHC}(=\mathrm{O})-4-\mathrm{MeC}_{6} \mathrm{H}_{4}$ was prepared by the one-step method of Atherton ${ }^{26}$ by reaction of $\mathrm{Ph}_{3} \mathrm{PMe}^{+} \mathrm{Br}^{-}$with $\mathrm{BuLi}$ and toluoyl chloride. Sulfonation was achieved by reaction with sulfur trioxide-pyridine complex (1.1 equiv) in dichloromethane at room temperature for $15 \mathrm{~h}\left({ }^{1} \mathrm{H} \mathrm{NMR}\left(\mathrm{CDCl}_{3}\right): \delta=6.96(\mathrm{~d}\right.$, 2f $\left.(\mathrm{H}, \mathrm{P})=10.0 \mathrm{~Hz} ; \mathrm{HC}-\mathrm{SO}_{3}^{-}\right){ }^{27}$ The ylide ligands were obtained by neutralization of the resulting zwitterion with aqueous solutions of sodium hydroxide and hexadecyltrimethylammonium hydroxide to a phenol phthalein end point. For key NMR data of the ligands obtained of. ref 15a. Complexes 1 were obtained by stirring a solution of bis(cycloocta-1,5diene)nickel ${ }^{28}$ with 1 equiv of the respective ylide ligand and 1 equiv of triphenylphosphane in THF for $15 \mathrm{~h}$ at room 
temperature (1a) ${ }^{27 b}$ and at room temperature for $14 \mathrm{~h}$, respectively, after heating for $1 \mathrm{~h}$ to $50{ }^{\circ} \mathrm{C}(\mathbf{1 b})$. The solvent was removed under reduced pressure, and the residue was dissolved in toluene. After filtration and concentration pentane was added to preci pitate the product (80-90\% yield). For NMR data of $\mathbf{1 a}$ and $\mathbf{1 b}$ cf. ref $\mathbf{1 5}$.

The salicylaldimine ligand was obtained by formic acidcatalyzed condensation of 2,6-diisopropylaniline with 3,5iodosalicylaldehyde, the product precipitating from methanol solution. ${ }^{7 a}$ The novel complex $\mathbf{2 a}$ was obtained by reaction of the sodium salt of the ligand with 1 equiv of trans-[NiClPh$\left.\left(\mathrm{PPh}_{3}\right)_{2}\right]^{29}$ in toluene according to ref $7 \mathrm{~b}$. The product was purified by crystallization from pentane solution at low temperature $\left(-65^{\circ} \mathrm{C}\right)$, affording $2 \mathrm{a}$ in ca. $70 \%$ yield. ${ }^{1} \mathrm{H}$ NMR (benzene- $\left.\mathrm{d}_{6}\right)$ : $\delta=8.1(\mathrm{br}, 1 \mathrm{H}), 8.0-6.7(\mathrm{~m}, 22 \mathrm{H}), 6.5-6.2$ $(\mathrm{m}, 3 \mathrm{H}) \mathrm{H}_{\text {arom }}$ and $\mathrm{C}(\mathrm{H})=\mathrm{N}$; 4.04 (septett, $3 \mathrm{~J}=7 \mathrm{~Hz}, 2 \mathrm{H}$; CHMeMe'); 1.31 and 1.10 (d, 3j $=7 \mathrm{~Hz}, 6 \mathrm{H}$ each; $\mathrm{CHMeMe}$ ). The presence of a small amount of a second compound $(<10 \%)$ is indicated by two doublets $(\mathrm{J}=7 \mathrm{~Hz})$ at 1.51 and 1.23 . Characteristic ${ }^{13} \mathrm{C}$ NMR resonances (benzene- $\mathrm{d}_{6}$ ): $\delta=166.0$ and $163.7\left(\mathrm{~d},{ }^{3} \mathrm{f}(\mathrm{C}, \mathrm{P})=2 \mathrm{~Hz} ; \mathrm{C}=\mathrm{N}\right.$ and $\left.\mathrm{C}-\mathrm{O}\right) ; 97.8\left(\mathrm{~d},{ }^{4} \mathrm{~J}(\mathrm{C}, \mathrm{P})\right.$ $=1 \mathrm{~Hz} ; \mathrm{C}-\mathrm{I}$ ); $74.2(\mathrm{C}-\mathrm{I}), 29.6,26.2$, and 23.4 (CHMeMe'; $\mathrm{CHMeMe}^{\prime}$, and $\mathrm{CHMeMe}$ ). ${ }^{31} \mathrm{P}$ NMR (benzene-d $\mathrm{d}_{6}$; internal $85 \%$ $\mathrm{H}_{3} \mathrm{PO}_{4}$ standard in coaxial tube): $\delta=23.9$. Complex $\mathbf{2 b}$ was obtained by reaction of the salicylaldimine ligand with 1 equiv of $\left[(\text { tmeda }) \mathrm{Ni}\left(\mathrm{CH}_{3}\right)_{2}\right]^{30}$ in the presence of a 10 -fold excess of pyridine in diethyl ether as a solvent at $-35^{\circ} \mathrm{C} .{ }^{7 a, 31}$ After stirring for $4 \mathrm{~h}$ at room temperature the red solution was filtered through a frit with dry Celite, and the solvent was removed under reduced pressure. ${ }^{1} \mathrm{H}$ NMR (benzene- $\mathrm{d}_{6}$ ): $\delta=$ $8.6(\mathrm{br}, 2 \mathrm{H}), 8.11\left(\mathrm{~d},{ }^{4} \mathrm{~J}=2 \mathrm{~Hz}, 1 \mathrm{H}\right), 7.1-7.0(\mathrm{~m}, 5 \mathrm{H}), 6.6$ (br, $1 \mathrm{H}), 6.3(\mathrm{br}, 2 \mathrm{H}) \mathrm{H}_{\text {arom }}$ and $\mathrm{C}(\mathrm{H})=\mathrm{N} ; 4.03$ (septett, 3) $=7$ $\mathrm{Hz}, 2 \mathrm{H}$; CHMeMe'); 1.47 and 0.99 (d, 3f $=7 \mathrm{~Hz}, 6 \mathrm{H}$ each; $\mathrm{CHMeMe}) ;-0.67$ (s, $3 \mathrm{H} ; \mathrm{Ni}-\mathrm{Me}$ ). Characteristic ${ }^{13} \mathrm{C}$ NMR resonances (benzene- $\left.\mathrm{d}_{6}\right)$ : $\delta=166.1(\mathrm{C}(\mathrm{H})=\mathrm{N}) ; 97.9$ and 73.2 (C-I);29.1, 25.4, and 23.7 (CHM eMe'; CHM M e' and CHM eMe'); $-6.0\left(\mathrm{Ni}-\mathrm{CH}_{3}\right)$. Satisfactory elemental analyses were obtained for $\mathbf{2} \mathbf{a}$ and $\mathbf{2} \mathbf{b}$. er. ${ }^{32}$

$\left[\mathrm{Rh}\left(\mathrm{CH}_{2}=\mathrm{CH}_{2}\right)(\mathrm{acac})\right]$ was prepared by the method of Cram-

Polymerization Procedure. Polymerization was carried out in a mechanically stirred $250 \mathrm{~mL}$ pressure reactor. Depending on the reaction pressure, a steel ( $>8 \mathrm{~atm}$ ) or glass vessel was utilized. The total volume of the added liquid phase (water and/or organic solvent) amounted to $100 \mathrm{~mL}$. The catalyst precursor and the activator were dissolved separately in a small amount of organic solvent. Both solutions were transferred to the reactor, containing the required amount of water and organic solvent, respectively. For copol ymerization experiments, a liquid mixture of norbornene with a small amount of toluene was added after addition of the catalyst solutions. The reactor was flushed with ethylene, and a constant ethylene pressure was applied as the vessel was rapidly heated to the specified temperature under vigorous stirring (1000 rpm). After the specified reaction time, the reaction was stopped by cooling and releasing the ethylene pressure. Precipitated polymers were isolated, washed with methanol, and dried in a vacuum. In experiments yielding a polymer latex, the latter was filtered through a funnel with glass wool prior to further workup and analysis. F or determination of the solids content the latex was added to an excess of methanol. The preci pitated polymers were isolated, washed with methanol, and dried in a vacuum. Copolymer solutions obtained in comparative experiments in neat toluene as a reaction medium were precipitated with excess methanol. Copolymers were washed with methanol and dried in a vacuum.

Acknowledgment. The authors thank R. Mülhaupt for his generous support. Financial support by BASF AG is gratefully acknowledged. F.M.B. thanks the Deutsche Forschungsgemeinschaft for a stipend (Graduiertenkolleg Strukturbildung in makromolekularen systemen). A generous loan of rhodium chloride was provided by Degussa-Huels AG. We thank G. Moerber for excellent technical assistance. Skillful assistance in GPC experiments by U. Westphal is gratefully acknowledged, and we thank A. Rossel for construction of highpressure equipment.

\section{References and Notes}

(1) (a) Emulsion Polymerization and Emulsion Polymers; Lovell, P. A., El-Aasser, M. S., Eds.; Wiley: Chichester, 1997. (b) Wäßrige Polymerdispersionen; Distler, D., Ed.; VCH: Weinheim, 1999. (c) Lagaly, G.; Schulz, O.; Zimehl, R. Dispersionen und Emulsionen; Steinkopff: Darmstadt, 1997. (d) Fitch, R. M. Polymer Colloids: a Comprehensive Introduction; Academic Press: San Diego, 1997.

(2) Transition metal catalysis in aqueous media has been investigated intensely in the context of two-phase catalysis for the preparation of low molecular weight compounds: Aqueous-Phase Organometallic Chemistry; Cornils, B., Herrmann, W. A., Eds.; VCH: Weinheim, 1998.

(3) (a) Ziegler Catalysts; Fink, G., M ülhaupt, R., Brintzinger, H. H., Eds.; Springer: Berlin, 1995. (b) Brintzinger, H. H.; Fischer, D.; Mülhaupt, R.; Rieger, B.; Waymouth, R. Angew. Chem. 1995, 107, 1255-83; Angew. Chem., Int. Ed. Engl. 1995, 34, 1143-70. (c) Britovsek, G. J. P.; Gibson, V. C.; Wass, D. F. Angew. Chem. 1999, 111, 448-68; Angew. Chem., Int. Ed. Engl. 1999, 38, 428-47. (d) Kaminsky, W.; Arndt, M. Adv. Polym. Sci. 1997, 127, 143-87.

(4) (a) Wilke, G. Angew. Chem. 1988, 100, 189-211; Angew. Chem., Int. Ed. Engl. 1988, 27, 185-206. (b) Peuckert, M.; Keim, W. Organometallics 1983, 2, 594-7.

(5) A much larger variety of ligands is applicable for the particular case of palladium-catalyzed alternating olefincarbon monoxide copolymerization: (a) Drent, E.; Budzelaar, P. H. M. Chem. Rev, 1996, 96, 663-81. (b) Sen, A. Acc Chem. Res. 1993, 26, 303-10. The specific responsibility of involve ment of CO in olefin-CO copolymerization for the reduced propensity for chain transfer is illustrated by the finding that the phosphine-based catalysts typically used dimerize ethylene in the absence of CO: (c) Drent, E.; van Broekhoven, J. A. M.; Doyle, M.J.J . Organomet. Chem. 1991, 417, 23551. (d) Sen, A.; Lai, T.-W.J . Am. Chem. Soc. 1981, 103, 46279. Ethylene-CO copolymerization has al so been carried out in water ${ }^{14 j-p} \mathrm{~A}$ feature specific to aqueous carbon monoxide copolymerizations is the possibility of facile activation of $\mathrm{Pd}-$ $\mathrm{OH}$ intermediates via the water-gas shift reaction. ${ }^{14 \mathrm{k}}$

(6) S, O ligands: (a) Bauer, R.; Chung, H.; Cannell, G.; Keim, W.; van Zwet, H. (Shell), US Pat. 3637636, 1972. N, N: (b) Keim, W.; Appel, R.; Storeck, A.; Krueger, C.; Goddard, R. Angew. Chem. 1981, 93, 91-2; Angew. Chem., I nt. Ed. Engl. 1981, 20, 116-7. (for the related reaction of $\alpha$-olefins of.: Moehring, V. M.; Fink, G. Angew. Chem. 1985, 97, 982-4; Angew. Chem., Int. Ed. Engl. 1985, 24, 1001-3). (c) Keim, W. Ann. N.Y. Acad. Sci. 1983, 415, 191-200. P, O: (d) Keim, W.; Kowaldt, F. H.; Goddard, R.; Krueger, C. Angew. Chem. 1978, 90, 493; Angew. Chem., Int. Ed. Engl. 1978, 17, 4667. (e) Ostoja-Starzewski, K. A.; Witte, J. Angew. Chem. 1987 99, 76-7; Angew. Chem., Int. Ed. Engl. 1987, 26, 63-4. (f) Ostoja-Starzewski, K. A.; Witte, J .; Reichert, K. H.; Vasiliou, G. In Transition Met. Organomet. Catal. Olefin Polym: Kaminsky, W., Sinn, H., Eds.; Springer: Berlin, 1988; pp 349-60. (g) Klabunde, U..; Ittel, S. D. J . Mol. Catal. 1987 41, 123-34. (h) Kurtev, K.; Tomov, A. J . Mol. Catal. 1994, $88,141-50$

(7) N, O: (a) J ohnson, L. K.; Bennett, A. M. A.; Ittel, S. D.; Wang L.; Parthasarathy, A.; Hauptman, E.; Simpson, R. D.; Feldman, J.; Coughlin, E. B. (DuPont) WO98/30609, 1998. (b) Wang, C.; Friedrich, S.; Younkin, T. R.; Li, R. T.; Grubbs, R. H.; Bansleben, D. A.; Day, M. W. Organometallics 1998, 17, 3149-51. (c) Younkin, T. R.; Connor, E. F.; Henderson, J . I.; Friedrich, S. K.; Grubbs, R. H.; Bansleben, D. A. Science 2000 287, 460-2. (d) Grubbs, R. H. Presented at the 219th ACS National Meeting, San Francisco, March 27, 2000 (paper 230).

(8) Ni, Pd: (a) J ohnson, L. K.; Killian, C. M.; Brookhart, M. J . Am. Chem. Soc. 1995, 117, 6414-5. (b) J ohnson, L. K. Mecking, S.; Brookhart, M. J. Am. Chem. Soc. 1996, 118, 267-8. (c) Killian, C. M.; Tempel, D. J ;; J ohnson, L. K.; Brookhart, M. J. Am. Chem. Soc. 1996, 118, 11664-5. (d) Mecking, S.; J ohnson, L. K.; Wang, L.; Brookhart, M. J . Am. Chem. Soc. 1998, 120, 888-99. (e) J ohnson, L. K.; Killian, C. M.; Arthur, S. D.; Feldman, J .; McCord, E.; McLain, S. J .; Kreutzer, K. A.; Bennett, M. A.; Coughlin, E. B.; Ittel, S. D.; 
Parthasarathy, A.; Tempel, D.; Brookhart, M. (UNC-Chapel Hill/DuPont) WO 96/23010, 1996. Co, Fe: (f) Small, B. L.; Brookhart, M.; Bennett, A. M. A. J . Am. Chem. Soc. 1998 120, 4049-50. (g) Britovsek, G. J . P.; Gibson, V.; Kimberley, B. S.; Maddox, P. J .; McTavish, S. J .; Solan, G. A.; White, A J. P.; Williams, D. J . Chem. Commun. 1998, 849-50. (h) Bennett, A. M. A. (DuPont), WO98/27124, 1998.

(9) Recent reviews on late transition metal catalysts for ol efin polymerization: (a) Reference 3c. (b) Mecking, S. Coord Chem. Rev. 2000, 203, 325-51. (c) Ittel, S. D.; J ohnson, L. K.; Brookhart, M. Chem. Rev. 2000, 100, 1169-204.

(10) J andeleit, B.; Schaefer, D. J .; Powers, T. S.; Turner, H. W.; Weinberg, W. H. Angew. Chem., 1999, 111, 2648-89; Angew. Chem., Int. Ed. Engl. 1999, 38, 2476-514.

(11) (a) Keim, W. Chem.-Ing.-Technol. 1984, 56, 850-3. (b) Vogt, D. In ref 2, pp 541-7.

(12) Beach, D. L.; Harrison, J . J . (Gulf), US Pat. 4711969, 1987.

(13) Wang, L.; Lu, R. S.; Bau, R.; Flood, T. C. J . Am. Chem. Soc 1993, 115, 6999-7000.

(14) For other transition metal catalyzed olefin polymerization reactions in water of. the following leading references. Butadiene polymerization: (a) Rinehart, R. E.; Smith, H. P.; Witt, H. S.; Romeyn, H. J . Am. Chem. Soc. 1961, 83, 4864-5. (b) Canale, A. J .; Hewett, W. A.; Shryne, T. M.; Youngman, E. A. Chem. Ind. 1962, 1054-5. (c) Rinehart, R. E.; Smith, H. P.; Witt, H. S.; Romeyn, H. J. Am. Chem. Soc. 1962, 84 4145-7. ROMP: (d) Novak, B. M.; Grubbs, R. H. J. Am Chem. Soc. 1988, 110, 7542-3. (e) Lynn, D. M.; Mohr, B. Grubbs, R. H.J . Am. Chem. Soc. 1998, 120, 1627-8. (f) Mohr B.: Lynn, D. M.; Grubbs, R. H. Organometallics 1996, 15, 4317-25. Other cyclool efin polymerizations: (g) Rinehart, R E. J . Polym. Sci., Part C 1969, 27, 7-25. (h) Natta, G. Dall'Asta, G.; Porri, L. Makromol. Chem. 1965, 81, 253-7. Alternating ol efin-CO copolymerization: (j) J iang, Z.; Sen, A. Macromolecules 1994, 27, 7215-6. (k) Verspui, G.; Papadogianakis, G.; Sheldon, R. A. Chem. Commun. 1998, 4012. (I) Bianchini, C.; Man Lee, H.; Meli, A.; Moneti, S.; Patinec V.; Petrucci, G.; Vizza, F. Macromol ecules 1999, 32, 385966. (m) Verspui, G.; Feiken, J .; Papadogianakis, G.; Sheldon, R. A. J . Mol. Catal. 1999, 146, 299-307. (n) Verspui, G. Schanssema, F.; Sheldon, R. A. Angew. Chem. 2000, 112 825-7; Angew. Chem., Int. Ed. Engl. 2000, 39, 804-6. (0) Lindner, E.; Schmid, M.; Wald, J .; Queisser, J . A.; Geprägs, M.; Wegner, P.; Nachtigal, C. J . Organomet. Chem. 2000, 602, 173-87. Also cf.: (p) Reppe, W.; Magin, A. US Pat. 2577208, 1948.

(15) (a) Held, A.; Bauers, F. M.; Mecking, S. Chem. Commun. 2000, 301-2. (b) Held, A.; Mecking, S. Chem. Eur. J . 2000, 6, 4623-9 and references cited therein.

(16) Shortly after our initial report, 15 a the results of independent investigations by others on $\mathrm{Ni}$ (II)-catalyzed polymerization in water were communicated: Tomov, A.; Broyer, J.-P.; Spitz, R. Macromol. Symp. 2000, 150, 53-8.
(17) Plöcker, U.; Knapp, H.; Prausnitz, J . Ind. Eng. Chem. Process Des. Dev. 1978, 17, 324-32. We thank J. Suhm (BASF AG) for kindly providing these data.

(18) Also, it should be noted that at the conditions employed ethylene is relatively close to its critcal point $\left(T_{c}=283 \mathrm{~K}, p_{c}\right.$ $=50$ bar), and therefore physical properties can differ strongly with small variations in experimental conditions.

(19) Chain transfer can be assumed to possess a relatively small dependence on ethylene concentration for these catalysts. An exact analysis of the comparative experiments in organic solvents with respect to the dependence of chain transfer on monomer concentration is complicated by the broad molecular weight distributions of the polymers obtained. However, for ethylene oligomerization by catalysts based on the same structural type of complexes, a corresponding mechanism has been proposed, based on kinetic studies. ${ }^{4 b}$

(20) van Krevelen, D. W. Properties of polymers: their correlation with chemical structure; their numerical estimation and prediction from additive group contributions; Elsevier: Amsterdam, 1994; pp 535-84.

(21) Deleted in proof.

(22) For previous notes on ethylene/norbornene copolymerizations by such $\mathrm{Ni}(\mathrm{II})$ catalysts of. ref 7c and Makovetsky, K. L.; Finkelshtein, E. S.; Bykov, V. I.; Bagdasaryan, A. K.; Goodall, B. L.; Rhodes, L. F. (BFGoodrich), WO 98/56837, 1998.

(23) For the properties of amorphous ethylene-cyclool efin copolymers prepared with metallocene catalysts cf.: Cherdron, $\mathrm{H}$ Brekner, M.-J .; Osan, F. Angew. Makromol. Chem. 1994, 223, 121-33.

(24) (a) Randall, J . C. J . Macromol. Sci., Rev. Macromol. Chem. Phys. 1989, C29, 201. (b) Axelson, D. E.; Levy, G. C.; Mandelkern, L. Macromolecules 1979, 12, 41.

(25) (a) Arndt-Rosenau, M.; Beulich, I. Macromol ecules 1999, 32, 7335-43. (b) Arndt-Rosenau, M.; Beulich, I. Macromol. Chem. Phys. 1998, 199, 1221-32. (c) Wendt, R. A.; Mynott, R. Hauschild, K.; Ruchatz, D.; Fink, G. Macromol. Chem. Phys 1999, 200, 1340-50. (d) Tritto, I.; Boggioni, L.; Sacchi, M C.: Locatelli, P. J . Mol. Catal. A: Chem. 1998, 133, 139-50.

(26) Aitken, R. A.; Atherton, J . I. J . Chem. Soc., Perkin Trans. 1 1994, 1281-84.

(27) (a) Nesmeyanov, N. A.; Zhuzhlikova, S. T.; Reutov, O. A. Dokl. Akad. Nauk. SSSR 1963, 151, 856-8. (b) Beach, D. L. Harrison, J J . (Gulf), Eur. Pat. Appl. 52929, 1981.

(28) Schunn, R. A. I norg. Synth. 1990, 28, 94-8.

(29) Hiodai, M.; Kashiwagi, T.; I keuchi, T.; Uchida, Y. J . Organomet. Chem. 1971, 30, 279-82.

(30) Kaschube, W.; Poerschke, K. R.; Wilke, G. J . Organomet. Chem. 1988, 355, 525-32.

(31) Also cf.: Klein, H.-F.; Bickel haupt, A. Inorg. Chim. Acta 1996 248, 111-4

(32) Cramer, R. Inorg. Synth. 1974, 15, 14-8. 